\title{
Is HbA1c still the Gold Standard for Glycemic Control?
}

\section{Vito Borzi*}

Department of Internal Medicine, Azienda Ospedaliera, Universitaria Policlinico - Vittorio Emanuele, Catania, Italy

*Corresponding author: Professor Vito Borzi, Department of Internal Medicine, Azienda Ospedaliera - Universitaria Policlinico - Vittorio Emanuele, Catania, Italy, Tel: +39 3386956220; E-mail: dott.vitoborzi@gmail.com

Received date: February 27, 2017; Accepted date: February 28, 2017; Published date: March 07, 2017

Copyright: (c) 2017 Borzi V. This is an open-access article distributed under the terms of the Creative Commons Attribution License, which permits unrestricted use, distribution, and reproduction in any medium, provided the original author and source are credited.

\section{Editorial}

Numerous intervention trials have shown that intensive glycemic control is effective in preventing microvascular complications in both type 1 and type 2 diabetes; whereas the reduction of macrovascular complications requires a much more prolonged treatment.

This led to the conclusion that diabetes was a cardiovascular disease diagnosed by hyperglycemia. It was reduced in this way the role of hyperglycemia, and especially of its intensive treatment, as a causal factor of cardiovascular complications [1].

Furthermore the demonstration that the hypertension and dyslipidaemias control was more effective than glycemic control has further strengthened this concept. In recent years, three large trials (ACCORD - ADVANCE -VADT) confirmed even the negative effects of tight glycemic control on cardiovascular risk in type 2 diabetes $[2,3]$.

It must however be noted that in these studies the risk of hypoglycemia was significantly increased in the intensive care arm; and, as we know, hypoglycemia is independently associated with an increased risk of mortality and vascular complications.

One might therefore conclude that achieving good glycemic control to prevent cardiovascular complications could be useless, if not harmful. The HbAlc is currently the gold standard of glycemic control and is commonly used to evaluate the effectiveness of therapeutic treatment [4].

But the inadequacy of the use of HbAlc as the only indicator of glycemic control was recently highlighted by the Swedish national registry data of type 1 diabetes. Patients with $\mathrm{HbAlc}<6.9 \%$ were still at risk of death, for any cause or cardiovascular causes, which was two times greater than non-diabetic subjects.

And because in type 1 diabetes, obesity, hypertension and dyslipidemia have a marginal role, the increased mortality in well compensated subjects strengthens the view that HbAlc cannot be considered the only marker of a good glycemic control [5].

We should probably consider not hyperglycemia "in itself", but the different types of hyperglycemia. The postprandial hyperglycemia could be an important independent risk factor, although still not demonstrated convincingly by evidence based medicine.

The alterations of endothelial dysfunction in post-prandial hyperglycemia could play an important role in the pathogenesis of cardiovascular complications. Furthermore it's important not to forget that a good control of post-prandial blood glucose significantly contributes to the optimization of HbAlc [6].

Also the glucose variability can be a significant independent risk factor for cardiovascular complications, even in subjects without diabetes. More fluctuations of blood glucose may be more damaging than a single episode of hyperglycemia both acute and a chronic hyperglycemic state.

Furthermore, the glucose variability facilitates hypoglycemic episodes, which, as well known, constitute a cardiovascular risk factor It has recently been demonstrated that hyperglycemia that follows to a hypoglycemic episode causes an impairment of ischemic preconditioning, aggravating the risk of vascular events, as well as in post-prandial hyperglycemia $[7,8]$.

From the above it is clear that the HbAlc represents only one aspect of glycemic control and therefore cannot be the gold standard of diabetes treatment. Probably now we have to have a broader view of the problem.

Therefore diabetes management becomes more challenging and perhaps diabetologist should go back a little to be again "Expert in Glycemia", a term that had been banned in recent years. Indeed a modern approach to glycemic control must provide for the achievement of an optimal level of HbAlc, but with a postprandial hyperglycemia control, a reduction in glycemic variability and a desirable absence of hypoglycemia.

Nowadays it's possible getting all this, thanks to the availability of better therapies and more effective instruments in the glucose monitoring. The incoming years will tell us whether this more complex view, but perhaps more physiological, will give us the desired results in terms of reduction in cardiovascular events.

\section{References}

1. Bonds DE, Miller ME, Bergenstal RM, Buse JB, Byington RP, et al. (2010) The association between symptomatic, severe hypoglycaemia and mortality in type 2 dia- betes: retrospective epidemiological analysis of the ACCORD study. BMJ 340: b4909.

2. Ceriello A, Hanefeld M, Leiter L, Monnier L, Moses A, et al. (2004) Postprandial glucose regulation and diabetic complications. Arch Intern Med 16:2090-2095.

3. Ceriello A, Kilpatrick ES (2013) Glycemic variability: both sides of the story. Diabetes Care 36: S272-S275.

4. Frontoni S, Di Bartolo P, Avogaro A, Bosi E, Paolisso G, et al. (2013) Glucose variability: an emerg-ing target for the treatment of diabetes mellitus. Diabetes Res Clin Pract 102: 86-95.

5. Grundy SM, Benjamin IJ, Burke GL, Chait A, Eckel RH, et al. (1999) Diabetes and cardiovascular disease: a statement for healthcare professionals from the Ameri- can Heart Association. Circulation 100: 1134-1146.

6. Lind M, Svensson AM, Kosiborod M, Gudbjörnsdottir S, Pivodic A, et al. (2014) Glycemic control and excess mortality in type 1 diabetes. N Engl J Med 371: 1972-1982.

7. Nathan DM, Kuenen J, Borg R, Zheng H, Schoenfeld D, et al. (2008) A1cDerived Average Glucose Study Group. Translating the A1C assay into estimated average glucose values. Diabetes Care 2008 31:1473-1478. 
Citation: Borzi V (2017) Is HbA1c still the Gold Standard for Glycemic Control?. J Diabetic Complications Med 2: e103. doi: 10.4172/2475-3211.1000e103

Page 2 of 2

8. Skyler JS, Bergenstal R, Bonow RO, Buse J, Deedwania P, et al. (2009) Intensive glycemic control and the prevention of cardiovascular events:
Implications of the ACCORD, ADVANCE, and VA Diabetes trials. Diabetes Care 32:187-192. 